\title{
Article
}

\section{Should all patients with generalised tonic-clonic seizures have their troponin levels measured?}

Egiz, Abdullah Mohammed abousaleh ma, Nautiyal, Hritik, AlShaharli, Radhi Forat Radhi, Fazail, Abdurrahman Hazrin and Teo, Bervin

Available at http://clok.uclan.ac.uk/37399/

Egiz, Abdullah Mohammed abousaleh ma ORCID: 0000-0003-0304-7982, Nautiyal, Hritik, Al-Shaharli, Radhi Forat Radhi, Fazail, Abdurrahman Hazrin and Teo, Bervin (2021) Should all patients with generalised tonic-clonic seizures have their troponin levels measured? British Journal of Hospital Medicine, 82 (4). ISSN 1750-8460

It is advisable to refer to the publisher's version if you intend to cite from the work. 10.12968/hmed.2020.0581

For more information about UCLan's research in this area go to

http://www.uclan.ac.uk/researchgroups/ and search for <name of research Group>.

For information about Research generally at UCLan please go to http://www.uclan.ac.uk/research/

All outputs in CLoK are protected by Intellectual Property Rights law, including Copyright law. Copyright, IPR and Moral Rights for the works on this site are retained by the individual authors and/or other copyright owners. Terms and conditions for use of this material are defined in the policies page. 


\section{British Journal of Hospital Medicine \\ Should all patients with generalised tonic-clonic seizures have their troponin measured? A case report and review of literature. \\ --Manuscript Draft--}

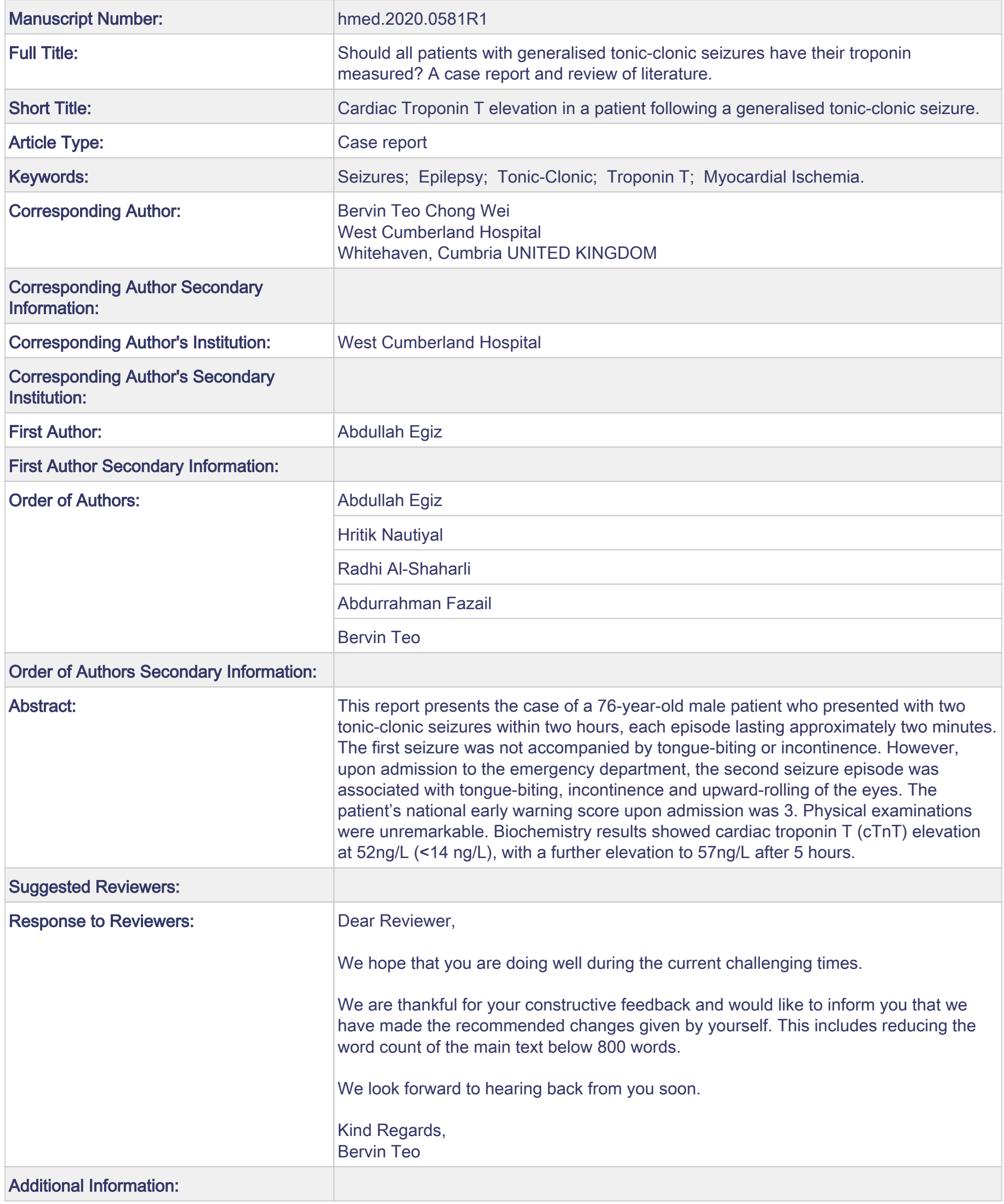


Please enter the word count of your 943

manuscript, excluding references and tables 


\title{
Should all patients with generalised tonic-clonic seizures have their troponin measured? A case report and review of literature.
}

\section{Short title: Cardiac Troponin T elevation in a patient following a generalised tonic-clonic seizure.}

\author{
Abdullah Egiz, Medical student ${ }^{1}$ \\ Hritik Nautiyal, Medical student ${ }^{1}$ \\ Radhi Al-Shaharli, Medical student ${ }^{1}$ \\ Abdurrahman Fazail, Medical student ${ }^{1}$ \\ Bervin Teo, Locum Medical Consultant ${ }^{2}$ \\ ${ }^{1}$ School of Medicine, University of Central Lancashire \\ ${ }^{2}$ West Cumberland Hospital, Whitehaven \\ Corresponding author: Bervin Teo, bervin.teo2@nhs.net, +44 (0) 7753458884
}

\begin{abstract}
This report presents the case of a 76-year-old male patient who presented with two tonic-clonic seizures within two hours, each episode lasting approximately two minutes. The first seizure was not accompanied by tongue-biting or incontinence. However, upon admission to the emergency department, the second seizure episode was associated with tongue-biting, incontinence and upward-rolling of the eyes. The patient's national early warning score upon admission was 3 . Physical examinations were unremarkable. Biochemistry results showed cardiac troponin T (cTnT) elevation at $52 \mathrm{ng} / \mathrm{L}(<14 \mathrm{ng} / \mathrm{L})$, with a further elevation to $57 \mathrm{ng} / \mathrm{L}$ after 5 hours.
\end{abstract}

\section{Keywords}

Seizures; Epilepsy; Tonic-Clonic; Troponin T; Myocardial Ischemia.

\section{Acknowledgment}

We thank the patient for giving us the privilege and honour to share his case and learn from it.

\section{Conflict of interest statement}

No, there are no competing interests for any author 


\title{
Should all patients with generalised tonic-clonic seizures have their troponin measured? A case report and review of literature.
}

\begin{abstract}
This report presents the case of a 76-year-old male patient who presented with two tonic-clonic seizures within two hours, each episode lasting approximately two minutes. The first seizure was not accompanied by tongue-biting or incontinence. However, upon admission to the emergency department, the second seizure episode was associated with tongue-biting, incontinence and upward-rolling of the eyes. The patient's national early warning score upon admission was 3. Physical examinations were unremarkable. Biochemistry results showed cardiac troponin T (cTnT) elevation at $52 \mathrm{ng} / \mathrm{L}(<14 \mathrm{ng} / \mathrm{L})$, with a further elevation to $57 \mathrm{ng} / \mathrm{L}$ after 5 hours.
\end{abstract}

\section{Case report}

A 76-year-old male brought in by ambulance to the emergency department due to an episode of nocturnal generalised tonic-clonic seizure (GTCS). Collateral history from the patient's wife revealed the seizure lasted for two minutes and it was associated with generalised stiffness of head, body and limbs with arched back followed by clonic jerks of head, body, limbs and upward eye-rolling. However, within two hours postadmission the patient experienced a second GTCS associated with tongue-biting, backward eye-rolling and incontinence, lasting for two minutes. Another history was then taken from the patient once he recovered. The patient denied antecedent symptoms such as chest pain, shortness of breath, fever, neck stiffness or visual changes. Moreover, there was no history nor symptoms of focal neurological deficit or cranial nerve involvement. The patient has a past medical history of unprovoked firstonset nocturnal seizure 4 months before this episode and has no known history of cardiac or renal diseases. Before admission, he was taking Fostair (200/6) and salbutamol (PRN).

On examination, the patient was alert and tachycardic with heart rate of $128 \mathrm{bpm} . \mathrm{He}$ had an oxygen saturation level of $94 \%$ on room air. Other vital signs and physical examinations were otherwise unremarkable. National early warning score (NEWS) was 3. His postictal Glasgow Coma Score (GCS) was 15/15.

An electrocardiogram (ECG) revealed voltage criteria for mild left ventricular hypertrophy $(\mathrm{LVH})$. Baseline blood samples were obtained and cTnT levels were also requested to rule out myocardial infarction as the potential source of the syncope. Biochemistry results showed an elevation of lactate at $13 \mathrm{mmol} / \mathrm{L}(0.1-1 \mathrm{mmol} / \mathrm{L})$ and a low bicarbonate at $16 \mathrm{mmol} / \mathrm{L}(22-26 \mathrm{mmol} / \mathrm{L})$ along with a $\mathrm{CTnT}$ elevation at $52 \mathrm{ng} / \mathrm{L}$ $(<14 \mathrm{ng} / \mathrm{L})$, with a further elevation to $57 \mathrm{ng} / \mathrm{L}$ after 5 hours. White cell count (WCC) was slightly elevated at $16.1 \times 10^{9} / \mathrm{L}\left(4-11 \times 10^{9} / \mathrm{L}\right)$ with neutrophils elevated at $10.8 \times$ $10^{9} / \mathrm{L}\left(2.0-7.5 \times 10^{9} / \mathrm{L}\right)$. Blood sugar levels were normal. Computed tomography of the brain did not reveal any cerebrovascular disease or space-occupying lesion.

The patient received Intravenous fluid therapy of $500 \mathrm{~mL}, 0.9 \%$ saline for fluid resuscitation. Subsequently, intravenous diazepam was administered at a rate of 5 mg per minute. $250 \mathrm{mg}$ of Levetiracetam was prescribed to be taken orally twice daily. $625 \mathrm{mg}$ of co-amoxiclav was administered as a precautionary empirical broadspectrum antibiotic considering the raised neutrophils, WCC and lactate. The patient 
responded well to the treatment and remained stable. He was discharged in two days and booked in for a neurological assessment in 2 weeks.

\section{Discussion}

Patients with GTC seizures who have elevated postictal cardiac troponin levels upon biochemical investigation are either elderly, have cardiac risk factors or both (Chatzikonstantinou et al., 2015). This can be highlighted by the fact that epilepsy studies involving young patients and with mean cohort ages of 21 and 44 consistently report no troponin elevation following seizures (Eskandarian et al., 2011; Hajsadeghi et al., 2009). In contrast, the study by Chatzikonstantinou et al (2015) which included a higher mean cohort age of 59 years, reported elevations in troponin levels following focal and generalized seizures. In addition, a systematic review by Sieweke et al. (2012), links cardiovascular ischemia as a contributing factor to seizure-related elevations in cTnT. Hence, our case is consistent with the findings of these studies as it reports troponin elevation postictally in a 76-year-old male patient.

There is limited research that investigates the link between seizures and troponin rise and therefore the exact pathophysiology is controversial (Fawaz et al., 2014). However, considering the autonomic innervation of the heart, periseizure cardiac changes are not surprising according to Jansen and Lagae (2010). It is postulated that the hyperadrenergic state during convulsions leads to a perfusion/demand mismatch resulting in myocardial injury and rise in troponins (Gaspard, 2019). Although troponins are considered to be specific to cardiac injury, troponin elevation has been reported in non-acute coronary syndrome events such as myocarditis, pericarditis, sepsis and rhabdomyolysis (Fawaz et al., 2014). As our patient did not have any of the above conditions, the possibility of a minor ischaemic myocardial injury due to the perfusion/demand mismatch seems more likely. It is valid to assume that the elderly are more prone to perfusion/demand mismatch injuries considering the age-related vascular changes that lead to greater myocardial demand (Fawaz et al., 2014).

We conclude through this case report that a GTCS cannot be assumed to be an innocent event for the patient's heart, especially in older age groups. A comprehensive postictal cardiovascular assessment is therefore warranted. More accurate imaging

modalities such as contrast-enhanced cardiovascular MRI for assessing subendocardial damage can be employed post-GTCS in patients with epilepsy to further investigate the link between cardiac injury and seizures.

\section{Learning points}

- GTC seizures seem to prompt the release of cTnT with predominance in patients with cardiovascular risk factors, especially in advanced age. This points towards the hypothesis that myocardial injury during the peri-seizure period causes the rise in cardiac troponins.

- A comprehensive postictal cardiovascular assessment is warranted including, but not limited to, an ECG, echocardiogram and troponins assay.

- Low clinical suspicion and lack of effort to explore for myocardial injury and other medical comorbidities post-GTC seizure could miss the diagnosis of potential co-existing conditions.

\section{Key words}

Seizures; Epilepsy; Tonic-Clonic; Troponin T; Myocardial Ischemia. 


\section{References}

Chatzikonstantinou, A., Ebert, A.D., Hennerici, M.G., 2015. Temporal seizure focus and status epilepticus are associated with high-sensitive troponin I elevation after epileptic seizures. Epilepsy Research 115, 77-80.

https://doi.org/https://doi.org/10.1016/j.eplepsyres.2015.05.013

Eskandarian, R., Asghari, N., Darban, M., Ghorbani, R., 2011. Cardiac Troponin Levels Following Complicated and Uncomplicated Epileptic Seizures. Archives of Medical Research 42, 439-442. https://doi.org/https://doi.org/10.1016/j.arcmed.2011.09.002

Fawaz, A., Nasreddine, W., Makke, Y., Atweh, S., Wazne, J., Arabi, M., Beydoun, A., 2014. Association of cardiovascular risk factors and troponin elevation after generalized tonic-clonic seizures. Seizure - European Journal of Epilepsy 23, 146-150. https://doi.org/10.1016/j.seizure.2013.11.006

Gaspard, N., 2019. Heartbreakers-Cardiac Stress After Uncomplicated Generalized Convulsive Seizures. Epilepsy currents 19, 246-248. https://doi.org/10.1177/1535759719856592

Hajsadeghi, S., Afsharian, S., Fereshtehnejad, S.-M., Keramati, M.R., Mollahoseini, R., 2009. Serum levels of cardiac troponin I in patients with uncomplicated epileptic seizure. Archives of Medical Research 40, 24-28. https://doi.org/10.1016/j.arcmed.2008.10.002

Jansen, K. \& Lagae, L. 2010, Cardiac changes in epilepsy. Seizure - European Journal of Epilepsy, vol. 19, no. 8, pp. 455-460. https://doi.org/10.1016/j.seizure.2010.07.008

Sieweke, N., Allendörfer, J., Franzen, W., Feustel, A., Reichenberger, F., Pabst, W., Krämer, H.H., Kaps, M. \& Tanislav, C. 2012. Cardiac Troponin I elevation after epileptic seizure. BMC Neurology, vol. 12, no. 1, pp. 58. https://doi.org/10.1186/1471-2377-12-58 